\title{
Narrativas social media y el prosumidor mediático ${ }^{1}$
}

Recibido: 17 de agosto de 2018

Aceptado: 4 de octubre de 2018

Publicado: 28 de noviembre de 2018
Gerardo Karbaum Padilla

gkarbaum@usmp.pe

Universidad de San Martín de Porres (Perú)

Resumen: Narrar es una acción necesaria, ejercida por la humanidad desde tiempos inmemoriales y que se prolonga hasta la actualidad. Los relatos son importantes para la sobrevivencia de la especie, ya que a través de estos se transmite el conocimiento de generación en generación y también se crea la identidad social de las comunidades. Cada época es definida por sus cambios sociales y culturales, pero también por sus avances tecnológicos. Estas tres dimensiones también influyen en la construcción de los relatos, tal como sucede en nuestros días, donde las historias cada vez más son producidas y difundidas por las redes sociales (dinámicas y comunicacionales) a las que se suma un nuevo narrador, el prosumidor mediático.

Palabras clave: Narrativa, transmedia, medios masivos, social media, contenido, prosumidor.

\begin{abstract}
Storytelling is a human action. Humankind practices it from memorial times until these days. Stories are important for species survival since through these knowledge is transfer from generation to the next one and social identity of communities is built. Each era is defined by social and cultural changes as well as technological innovations. At the same time, these three concepts weighs in the creation of stories, as set out today: stories are produced and widespread on social media as communicational actions, which are linked by a new teller: the media prosumer.
\end{abstract}

Key words: Narrative, Transmedia, Mass Media, Social Media, Content, Prosumer.

1 Diseño gráfico y asistencia de investigación: Andrea Oré Campos \& Grecia Loayza Matos. 


\section{Introducción}

Narrar es uno de los actos más importantes que realiza el ser humano para sobrevivir. Desde los albores de la humanidad, contar historias se convirtió en una necesidad ineludible. A través de estas, los hombres han transmitido conocimientos y se lograba que los grupos humanos crearan lazos sociales necesarios para dotar de sentido a la comunidad. Con los mitos y las leyendas, los hombres imaginaban la procedencia de sus civilizaciones.

Narrar se ha convertido en un acto utilitario para garantizar la existencia, ya que las historias provocan el deleite de quien las oye, lee o ve. Por ese motivo, los narradores siempre han gozado de valoración social: desde los jefes tribales (que explicaban el origen de sus pueblos en torno a una fogata) hasta las grandes corporaciones mediáticas, las cuales generan infinidad de relatos para ser consumidos globalmente. Según Gutiérrez (2003),

desde siempre, contar historias tuvo la fascinante capacidad de congregar a las personas alrededor de una fogata, en torno de una mesa o de una pantalla, transformando la narración en un ritual de cohesión social y de vivencias personales, construidas a través de los relatos: narrativas que fueron creando las más bellas leyendas sobre conquistas, pérdidas, tragedias y pasiones; historias que avanzan y retornan, que se mezclan y transforman, fundando, por siglos, los mitos de nuestra memoria y las fábulas más representativas de nuestro imaginario. En este universo de quimeras y realidades, la narración ha tenido muchas fases, rupturas y evoluciones tanto en los modos de relatar como en los medios a través de los cuales se cuentan las historias. Especificar y definir estas formas de representar significa recuperar las claves que sustentan todas las narrativas construidas por la propia historia de la humanidad, la de nuestra identidad y cultura (p. 21).

Los relatos son historias y a la vez convergencia de intereses sociales. En torno a lo primero, se entiende como la construcción de discursos donde interactúan elementos narrativos como los personajes, acción, espacio y tiempo. En cuanto a lo segundo, hay que asumirlos como creaciones colectivas donde las comunidades encuentran respuestas a sus preguntas más profundas (como su origen o destino) además de generar, a partir de ello, su sentido de identidad comunitaria.

En la actualidad, los relatos han evolucionado de tal manera que se producen y consumen como nunca antes en la humanidad. La difusión de los mismos siempre estuvo condicionada al soporte donde se plasmaban: el primero fue la voz humana, cuya limitación eran su permanencia en el tiempo y el espacio. Luego la escritura y la imprenta permitieron superar esas condiciones. Cada tecnología ha ido modificando los modos de producción y las formas discursivas. La aparición de los medios masivos en el siglo XX transformó la producción y consumo de los relatos, unos pocos los generaban y muchos los consumían. Sin embargo, la aparición de la web 2.0 y las redes sociales ha provocado que los mass media pierdan parte de su hegemonía y los discursos también se dan ahora en las redes sociales, donde se suma un nuevo generador de contenidos, el prosumidor mediático. 


\section{Objetivos y metodología}

El propósito de este artículo es plantear una nueva línea de investigación en cuanto a las narrativas social media, entendiéndolas como una dinámica comunicacional en la que se crean discursos para los medios sociales, en especial de las redes sociales. La finalidad es plantear relaciones en los siguientes ámbitos temáticos y desarrollar los siguientes objetivos:

- Definir qué son las narrativas social media.

- Determinar la importancia del prosumidor mediático en este contexto discursivo y caracterizar su evolución asociada al avance de las tecnologías de producción de contenidos.

- Describir las dinámicas comunicacionales que convergen en las redes sociales y que permiten que tanto usuarios como medios masivos generen relatos que se crean de acuerdo con las posibilidades discursivas que cada red ofrece.

- $\quad$ Resumir la progresión de los relatos de acuerdo con sus intenciones y con la evolución de las tecnologías que los han posibilitado.

Este trabajo es de enfoque cualitativo, siguiendo una investigación previa consignada en Karbaum (2018), en el cual se plantea la idea de que las narrativas transmedia están evolucionando a un estadio en donde las redes sociales ya tienen un papel protagónico en la generación de relatos para el cibernauta contemporáneo.

Para la realización del trabajo, se ha consultado bibliografía referida a ejes temáticos como: narrativa, narrativa transmedia, redes sociales, medios masivos y convergencia digital. A partir de su reflexión, se aplica un proceso de observación de la realidad mediática local, acopiando publicaciones realizadas en Facebook. Los propósitos de este trabajo se enfocan en una muestra aleatoria, de la cual se analizan sus elementos discursivos y los procesos aplicados para su producción.

\section{La importancia de narrar}

Tal es la importancia de los relatos en la existencia del hombre, a nivel personal y social, que Fisher, citado por Fernández \& Galguera (2009, p. 89) plantea la teoría del "paradigma narrativo", la que sostiene que toda comunicación es narración en sí misma. El ser humano es narrativo por naturaleza y contar historias es una condición innata. Bajo este paradigma, todo acto comunicativo lleva en sí la intención de un relato. Fisher afirma que la importancia de la narración en la vida humana se da porque a través de ella los hombres "comprenden su vida como una serie de historias, con conflictos, actores, inicios desarrollo y finales" (Fernández \& Galguera, 2009, p. 89). Fisher plantea en su teoría que los seres humanos aplican a sus relatos el método de la racionalidad narrativa por medio del cual cada individuo hace una valoración retórica de las historias evaluando su coherencia interna, a partir de ese juicio elabora conclusiones y establecerá 
predisposiciones (favorables, neutrales o negativas) hacia el relato (Fernández \& Galguera, 2009, p. 89)

El paradigma narrativo sostiene que una historia, para ser sólida, debe poseer coherencia interna. Fernández y Galgera (2009) identifican sus tres tipos constitutivos:

- $\quad$ Coherencia estructural: en este caso se incide en la congruencia interna de los elementos de una historia: es decir, una parte ha de llevar a la otra y la trama ha de ser siempre clara para que el oyente no detecte la ausencia de coherencia.

- Coherencia material: se refiere a la congruencia externa de una historia en comparación con otras narraciones sobre el mismo tema. Si una historia parece muy alejada de la visión que teníamos sobre un tema concreto a partir de otras narraciones, nuestra reacción puede ser poner en duda su coherencia material, y por consiguiente la historia.

- Coherencia de los personajes: este aspecto está relacionado con la credibilidad de los actores de la narración; si los personajes principales no resultan creíbles, posiblemente nos lleven a poner en duda toda la historia. (p. 89).

Esa solidez de las historias se logra a través de la estructuración de sus elementos y de su eficaz interrelación, es decir, que la coherencia discursiva se logra por la correcta interacción entre los personajes, espacios, acciones y tiempos que configuran las historias. Estos elementos están presentes en todos los relatos, sean de ficción o realidad. Lo que distingue a cada uno de estos es el tratamiento que se hace de la forma y el fondo que los define como parte de un formato o género, lo cual implica la construcción argumental por parte del creador. En otras palabras, cada narración tiene una estructura que permite su decodificación por parte del público, la que es reconocible de acuerdo con los modos discursivos que aplica el narrador. Según Gutiérrez (2006), "la comprensión de las estructuras narrativas está ligada a la formación de un lenguaje interno sin el cual el cerebro sería incapaz de continuar un discurso tal" (p. 10).

Narrar es también evolucionar y las historias promueven el desarrollo en dos dimensiones: una cognitiva y otra tecnológica. En la primera se hace referencia a la contribución que tienen los relatos para entender el mundo y las circunstancias que genera la vida humana. La segunda se entiende porque el ser humano ha ido creando soportes e instrumentos técnicos que han permitido la preservación y la distribución de los relatos, superándose las condicionantes que suponen el tiempo y el espacio. Con esto se logra que las historias trasciendan y sean compartidas con la comunidad, lo que permite que el hombre logre representarse a sí mismo, plasmando en estas sus intereses individuales y colectivos. El éxito de toda narración radica en su capacidad de ser verosímil y comprensible por parte de los destinatarios. Según Gutiérrez (2006), "cuando el hombre adquiere la capacidad de representar tiende a una mimesis y reinterpretación que le supone una capacidad de abstracción".

Dentro de la dimensión cognitiva de las narraciones, existe una creación humana sin la cual no se podría estructurar las historias, el lenguaje. En un primer momento, el hombre 
crea los sonidos vocálicos y con ellos comienza a darle nombre a las cosas que le rodean y también a lo que siente. A partir de allí tiene el instrumento necesario para la creación de los primeros relatos orales con los que se convierte en "un ser simbólico, y a través de la evolución de miles de años ha ido creando simbologías cada vez más ricas y más complejas" (Rodríguez, 1989, p. 33).

La voz no solo se constituye en su único soporte comunicacional. La pintura también le sirve de método expresivo: las cavernas se convirtieron en el soporte que comunicaba sus preocupaciones cotidianas, sus anhelos más íntimos y sus deseos colectivos. Además, tiene una diferencia fundamental sobre la voz, la permanencia. Con la voz se articulan sonidos y forma palabras que permiten la construcción relatora. En cambio, la imagen pictórica supone una síntesis gráfica que es interpretada a partir de lo que se infiere a través de trazos y colores. Al respecto, Karbaum (2017) afirma que:

Las pinturas insinúan relatos, preservan momentos hacen que el observador reconozca situaciones que sus autores vivieron, algunas tan cotidianas, sin desmerecer su importancia, como la consecución de alimentos a través de la caza o el cultivo. Otras tan profundamente espirituales como las que representan a sus divinidades. El hombre ha descubierto que puede crear registros pictóricos de sí mismo, su presente queda plasmado, pero con el tiempo esos materiales gráficos servirán a otros hombres para entender cómo se fue gestando la civilización. Con el paso del tiempo, las paredes cavernarias fueron reemplazadas por otro tipo de soportes como la cerámica, vasijas, telas y otro tipo de artefactos que fueron decorados con dibujos que representaban las historias o mitos de los pueblos (p. 43).

Ante la precariedad de lo sonoro, el hombre inventa un recurso para hacer que los relatos se trasladen en el tiempo y en el espacio: la escritura. Al poder representar sonidos a través de la escritura, el hombre logró que las historias tengan una mayor permanencia en el tiempo y puedan ser transmitidos de generación en generación. Además, podían ser trasladados a través de distintos espacios, lo que permitió la difusión progresiva de las diferentes manifestaciones culturales $\mathrm{y}$, por ende, de las distintas formas de entender la realidad. Así, la capacidad discursiva del hombre asume nuevas potencialidades, "gracias al mismo ser humano, su historia se puede leer, saborear y escuchar. Se lee en enciclopedias o novelas literarias; y se escucha a través de las tradiciones preservadas que aun suenen en la actualidad" (Lechuga, 2015, p. 13).

Literatura e historia se sustentan en la escritura. En la primera los relatos se plasman en textos y en la segunda los hechos se registran en estos. Sin embargo, no son los únicos ámbitos discursivos en donde los hombres desarrollan relatos. El ser humano crea discursos en todos los espacios sociales donde se desenvuelve, es una necesidad. En cada uno de estos va elaborando modos y estructuras que responden a sus necesidades internas y colectivas. De acuerdo con Rincón (2006),

el periodismo cuenta y comprende el presente, la vida cotidiana y pública, mientras que, por ejemplo, la teoría política comprende la vida democrática y sus 
instituciones; la literatura construye las imágenes del espíritu y estudia las formas narrativas y el lenguaje como expresión; la filosofía comprende los fundamentos morales y la pregunta por el sentido, y la historia crea conciencia sobre el pasado y comprende el devenir de la sociedad (p. 122).

La posibilidad evolutiva de estos ámbitos narrativos propicios (para el desarrollo de relatos) siempre está acompañada de las predisposiciones tecnológicas. Cada época está marcada por los dispositivos que se usan para relatarla, es una relación bicondicional. En tal sentido, el siguiente paso tecnológico discursivo lo marcó la creación de la imprenta. Con esta, las historias, el conocimiento y la cultura en general pudieron difundirse de mejor manera.

Al evolucionar la tecnología, se despierta en el ser humano un deseo de superarla, de trascender el statu quo e innovar. En ese propósito de narrar la realidad (lo más fidedignamente) las imágenes siempre han tenido un rol preponderante. La pintura alcanzó su máximo propósito representativo con el estilo figurativo, pero para inicios del siglo XIX, la invención de la fotografía cumple de mejor manera ese objetivo. Más adelante, la creación del cinematógrafo (1895) y demás dispositivos audiovisuales de la época iniciaron una transformación en la forma como se creaban y se consumían los relatos.

La invención del cine supuso una forma innovadora de construir relatos. Las imágenes proyectadas en movimiento tienen la capacidad de generar una sensación de realismo muy próxima a la percepción que los humanos tienen al observar la realidad. Al inicio, las historias eran adaptadas de otros ámbitos narrativos (literatura o teatro), puesto que no tenía una narrativa propia. Como se aprecia en las primeras películas, la cámara asume una posición fija y los hechos ocurren frente a ella en encuadres de planos abiertos, como si fueran puestas en escena teatrales filmadas. Sin embargo, fueron apareciendo pioneros que innovaron en la creación de un lenguaje propio, desarrollándose así la discursividad fílmica. Alice Guy (considerada como la primera narradora de ficción cinematográfica) y los miembros de la Escuela de Brigthon (Inglaterra) impusieron las innovaciones de encuadre y montaje que definieron el lenguaje audiovisual tal como se utiliza en la actualidad.

Hasta la primera mitad del siglo XX coexistían tres grandes ámbitos narrativos (la radio, el cine y los medios impresos) hasta que irrumpió un nuevo medio que se convirtió en el hegemónico, la televisión. Con su aparición se configuraba un ecosistema mediático de creaciones narrativas masivas. El medio se convertía en un actor social más que generaba dinámicas discursivas propiciando hábitos de consumo, de acuerdo con las características técnicas de cada uno. En tal sentido, López Suárez (2012) afirma lo siguiente:

Básicamente el concepto de "medio" reposa sobre la idea de "centro", sugiriendo el valor de relación; es decir, hace referencia a un instrumento o factor de engarce entre dos elementos distantes o inconexos entre sí a los que vincula desde su posición. De ahí que pueda definirse como instrumento destinado a emitir, transmitir, preservar o recibir un mensaje que puede estar constituido por sonidos, palabras, escritura, imágenes (fijas o en movimiento) (p. 2). 
El siglo XX es el de los medios masivos: nunca antes la humanidad había creado estructuras técnico discursivas que pudiesen llegar con tanta facilidad a grandes cantidades de personas. Sucedería también un cambio fundamental: cuando los medios masivos analógicos estaban en su esplendor, se incorpora la tecnología digital, homogeneizándose los procesos de realización, distribución y comercialización de contenidos, ya que toda la cadena de producción se sustenta bajo una misma tecnología que opera bajo los principios del código binario. Además, la evolución de esta tecnología permitió el desarrollo de otro medio que amplió las capacidades comunicacionales de la humanidad, la Internet. McLuhan (2009) predijo este panorama extensivo de forma certera:

Tras tres mil años de explosión, mediante tecnologías mecánicas y fragmentarias, el mundo occidental ha entrado en implosión. En las edades mecánicas extendimos nuestro cuerpo en el espacio. Hoy, tras más de un siglo de tecnología eléctrica, hemos extendido nuestro sistema nervioso central hasta abarcar todo el globo, aboliendo tiempo y espacio, al menos en cuanto a este planeta se refiere. Nos estamos acercando a la fase final de las extensiones del hombre: la simulación tecnológica de la conciencia, por la cual los procesos creativos se extenderán, colectiva y corporativamente al conjunto de la sociedad humana, de un modo muy parecido a como ya hemos extendido nuestros sentidos y nervios con los diversos medios de comunicación (p. 27).

\subsection{La narrativa audiovisual y la convergencia de los medios}

El cine, la televisión y la Internet difunden historias y gran parte de estas tienen un carácter diferencial porque utilizan imágenes en movimiento. La creación de las mismas se inicia con la cinematografía, luego estas técnicas discursivas se trasladan a la televisión y después a la web. Cuando se trata de contar relatos con imágenes en movimiento, se habla de narrativa audiovisual, la cual está constituida por dos dimensiones (figura 1): la historia (fondo o contenido) y el lenguaje audiovisual (forma o continente).

Figura 1: Dimensiones constitutivas de la narrativa audiovisual.

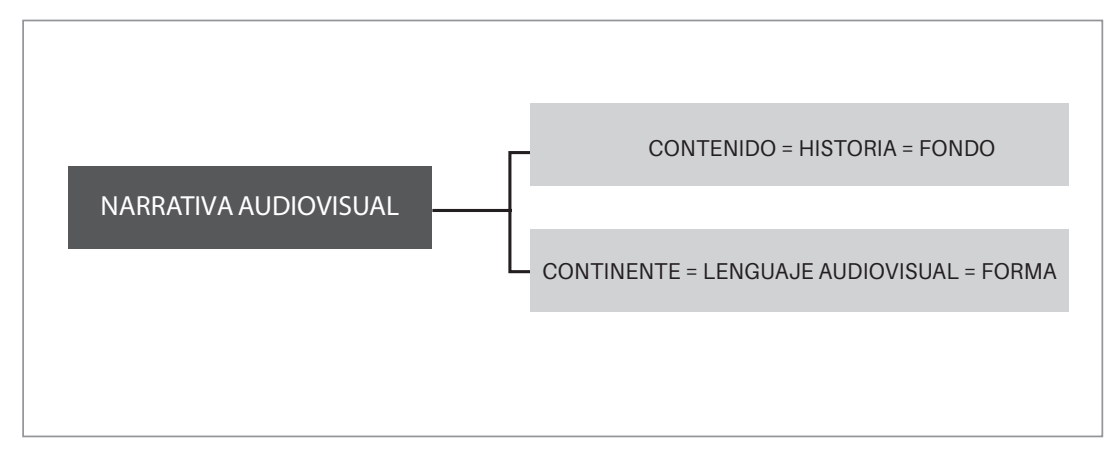

Fuente: Elaboración propia. 
El contenido es la historia que se le presenta al espectador. Posee cuatro elementos constitutivos: los personajes, la acción, el espacio y el tiempo. La variedad en la utilización de cada uno de estos está determinada por el género, formato o programa en el que se vaya a construir. Los elementos también están condicionados por los modelos narrativos de cada medio y por las conductas que generan en el espectador ${ }^{2}$. En cuanto a la interrelación de los elementos narrativos y su funcionalidad dentro de la trama, Gutiérrez (2003) afirma que los personajes son partícipes de una estructura argumental donde a través de sus acciones consolidan "una estructura narrativa que da cuenta de una serie de acontecimientos que se exponen a través de voces y diálogos, siempre contextualizados en un tiempo y en un espacio determinados que los representa" (p. 22).

Esta conjunción de personajes, espacios, tiempos y acciones se materializa en los relatos audiovisuales a través de imágenes y sonidos. A la suma de estos elementos se le denomina lenguaje audiovisual, "siguiendo pautas que le permiten crear un producto cinematográfico, televisivo o web con fines informativos, educativos, de entretenimiento o publicitarios" (Karbaum, 2018, p. 109).

Las imágenes audiovisuales tienen la particularidad de representar el movimiento. Por lo tanto, permiten mostrar acciones ejecutadas por los personajes en distintos espacios y tiempos. Poco a poco, el lenguaje audiovisual se fue desarrollando en cuanto a la explotación narrativa del encuadre, el montaje y la banda sonora, así como a las dimensiones formales de construcción discursiva. Este lenguaje audiovisual está siendo utilizado por la Internet, que está teniendo su mayor nivel de producción y consumo a través de los medios y redes sociales (figura 2).

Figura 2: Penetración de Internet en Latinoamérica.

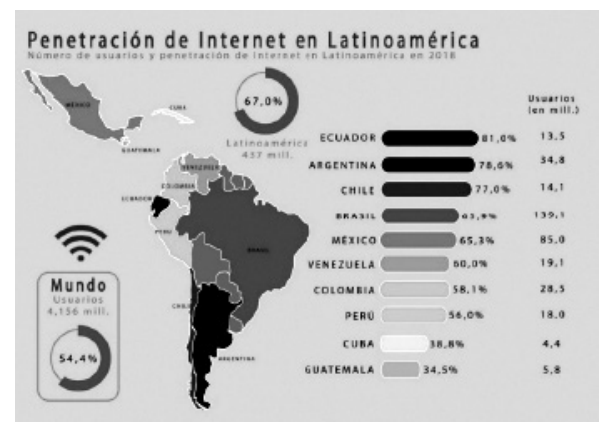

Fuente: Statista (2018).

2 Cada medio ha ido generando conductas de consumo relacionadas con sus características técnicas. El cine es visto en una sala donde se proyecta el contenido. La televisión (durante sus cuarenta décadas de hegemonía como medio de comunicación masivo) permitió al espectador ver los programas de manera individual o colectiva en cualquier lugar donde existiera un receptor que pudiera captar la señal televisiva. Esta cualidad se ha visto potenciada con la implementación de la TDT, que permite transmitir la señal a dispositivos móviles, como celulares o televisores en movimiento. Durante décadas, estos hábitos estuvieron condicionados a la programación de la cadena televisiva y a la estacionalidad en el hogar. Cabe destacar que la Internet se caracteriza por un consumo asincrónico e interactivo por parte del usuario. 


\subsection{De la narración transmediática a la social media}

La evolución de los relatos pasó a otro nivel cuando se abrió la posibilidad de distribuir las historias por distintos medios y que los usuarios las pudiesen extender por diversas plataformas o crear versiones propias de estas. Estas dos características son los ejes fundacionales de las narrativas transmedia ${ }^{3}$. Este concepto explica cómo y porque los relatos se difunden a través de distintas plataformas y porque son tan importantes en la vida de las personas y cómo estas últimas se apropian de las historias y las extienden, difunden y crean sus propias versiones.

Este concepto ayuda a describir lo que estaba sucediendo en la creación y en el consumo de historias, entendiéndose así procesos discursivos en distintas áreas narrativas. Según Rejano, citado por Karbaum (2018):

En un principio, este término se relacionaba con el mundo del entretenimiento, pues eran el cine, los videojuegos y los cómics los medios que más se utilizaban para narrar de modo transmediático. Sin embargo, la evolución de este ecosistema mediático ha permitido la incorporación de nuevos medios, cuyas estrategias comunicativas amplían la experiencia transmedia a disciplinas como la publicidad, la educación o el periodismo (p. 14).

A partir de este planteamiento se han diversificado distintas miradas para entender cómo se está narrando en la actualidad. Con respecto a la forma de entender los discursos transmediáticos, Henry Jenkins postuló siete principios (tabla 1) que caracterizan al contexto mediático narrativo actual. Estos lineamientos son aplicables a los distintos ámbitos discursivos, tales como la publicidad, el periodismo, la ficción o el entretenimiento.

Tabla 1: Los 7 principios de las narrativas transmedia planteados por Jenkins.

\begin{tabular}{|l|l|}
\hline $\begin{array}{l}\text { Expansión } \\
\text { versus } \\
\text { profundidad }\end{array}$ & $\begin{array}{l}\text { Hace referencia a las posibilidades de viralización de los contenidos a través de Internet } \\
\text { y las redes sociales, lo que permite su evolución. Esto contribuye a elevar la valorización } \\
\text { económica y simbólica de los relatos. La profundidad viene a ser la interiorización que } \\
\text { realizan los consumidores de aquellas historias por las que sienten afinidad. Esta filiación } \\
\text { los motiva a involucrarse con estas. }\end{array}$ \\
\hline $\begin{array}{l}\text { Continuidad } \\
\text { multiplicidad }\end{array}$ & $\begin{array}{l}\text { La continuidad hace referencia al propósito de permanencia que debe haber al construir } \\
\text { un relato, por más que sea difundido en diversos medios. Se trata de mantener la esencia } \\
\text { viene a ser la creación de experiencias narrativas por parte de los usuarios que amplían las } \\
\text { posibilidades narrativas de los personajes y sus circunstancias desde nuevas perspectivas. }\end{array}$ \\
\hline
\end{tabular}

3 Concepto acuñado por el investigador norteamericano Henry Jenkins. 


\begin{tabular}{|c|c|}
\hline $\begin{array}{l}\text { Inmersión } \\
\text { versus } \\
\text { extracción }\end{array}$ & $\begin{array}{l}\text { La inmersión es la capacidad que tiene el espectador de entrar y recorrer todos los mundos } \\
\text { que componen el universo narrativo del relato transmedia, mientras que la extracción es la } \\
\text { posibilidad que tienen los fans de tomar elementos y simbologías de ese universo e integrarlas } \\
\text { en su vida personal. Esto se da, por ejemplo, en el caso de los gadgets, juguetes u objetos } \\
\text { de uso cotidiano diseñados con personajes, escenarios u acciones que pertenecen a un relato } \\
\text { (tazas de Batman, lapiceros de La guerra de las galaxias, etc.). También se manifiesta en } \\
\text { el fenómeno cosplay, donde los fanáticos se visten y actúan como sus personajes favoritos. }\end{array}$ \\
\hline $\begin{array}{l}\text { Construcción } \\
\text { de mundos }\end{array}$ & $\begin{array}{l}\text { Los relatos, para ser creíbles, deben tener coherencia e interrelación entre su forma y fondo. } \\
\text { La historia debe ser consistente en cuanto a sus personajes, espacios, tiempos y acciones. } \\
\text { Cada uno de estos elementos, al ser bien construidos, establecen una sinergia discursiva que } \\
\text { permite la efectividad narrativa. Esa prerrogativa también debe ser considerada a la hora } \\
\text { de crear un universo narrativo transmediático, mediante la planificación de la producción y } \\
\text { distribución a través de múltiples plataformas. }\end{array}$ \\
\hline Serialidad & $\begin{array}{l}\text { Consiste en publicar episodios o ediciones temporalmente frecuentes. Con ello se consigue } \\
\text { la fidelización de la audiencia al relato y se garantiza la rentabilidad económica por el } \\
\text { tiempo en que el público siga consumiéndolos. En el contexto actual de las narrativas } \\
\text { transmedia, esta estrategia también se tiene en cuenta, pero las posibilidades de serialización } \\
\text { que ofrece cada medio o plataforma (por donde se distribuirá la franquicia narrativa) deben } \\
\text { ser consideradas. }\end{array}$ \\
\hline Subjetividad & $\begin{array}{l}\text { Es la posibilidad de exponer y explorar el relato desde los distintos puntos de vista que } \\
\text { tienen los personajes que lo conforman. En el cine, un antecedente importante es Rashomon } \\
\text { (1950), de Akira Kurosawa, y en la televisión, la serie Lost. Ese método narrativo (ya } \\
\text { explotado en la época pretransmedia) también es aplicado en el contexto actual. Con esto se } \\
\text { logra ampliar la historia a la vez que se va expandiendo por distintas plataformas. También } \\
\text { es cada vez más común ver cómo personajes que ocupaban roles complementarios en } \\
\text { programas de televisión, radio o hasta videojuegos, luego son protagonistas de sus propias } \\
\text { historias. Estas realizaciones son denominadas spin-off. }\end{array}$ \\
\hline Realización & $\begin{array}{l}\text { Tiene como principal protagonista a los prosumidores, quienes asumen el rol de realizadores } \\
\text { y se suman a la extensión discursiva de su franquicia narrativa preferida como las que plasman } \\
\text { a través de los productos fanfiction. Su vinculación con esta es muy fuerte, razón que los } \\
\text { motiva a crear contenido con sus propios recursos. Esta facultad se ha visto potenciada en } \\
\text { la última década gracias a la digitalización de los equipos de registro y postproducción, la } \\
\text { masificación de los smartphones y la expansión de Internet y las redes sociales. }\end{array}$ \\
\hline
\end{tabular}

Fuente: Karbaum (2018, pp. 53-54).

La narrativas transmedia sirven para entender los relatos actuales, pero no son un concepto estático porque se reformula constantemente, a la par que las historias evolucionan continuamente. En estos tiempos de permanente desarrollo tecnológico, los medios de comunicación están transformándose de estructuras analógicas mono-mediáticas a organizaciones digitales multiplataforma, generando contenidos para diversos medios a partir de sistemas de producción, las cuales abastecen las necesidades de un público cada vez más disperso y que accede a las historias desde distintos dispositivos. 
A esa realidad mediática se han sumado los social media, que son un conjunto de plataformas, aplicaciones y herramientas de comunicación digitales en línea, creados a partir del desarrollo de la web 2.0. Estos permiten la producción, interacción, colaboración y difusión de contenidos entre los usuarios de Internet de manera globalizada. Pertenecen a este conjunto de medios sociales los blogs, las wikis, las aplicaciones de mensajería y las redes sociales.

En la actualidad, estas últimas gozan de mucha aceptación por parte de los usuarios, porque permiten que los prosumidores generen y compartan contenido. Además, facilitan la interacción entre ellos. A diferencia de lo sucedido en el siglo XX (donde los mass media ocupaban un rol predominante en la comunicación de masas), estos medios se han convertido en espacios narrativos donde los usuarios son participes activos en la creación de historias, Así, se plantea el término de "narrativas social media" para nombrar a estas nuevas dinámicas discursivas. Según Karbaum (2018):

Las narrativas social media se entienden como los procesos de comunicación en donde los relatos tienen como ámbito de producción, distribución, consumo e intercambio a los medios sociales, en especial a las RR. SS., las cuales pueden contener producciones narrativas de otros medios antecedentes, como el cine, la televisión, la radio, los videojuegos, etc., así como contenidos propios generados para ellas. En este contexto, el prosumidor asume un rol fundamental, ya que ha alcanzado niveles nunca antes vistos para la difusión de sus creaciones narrativas (p. 127).

Dentro este contexto mediático, el crecimiento de las redes sociales ha sido exponencial en poco más de una década: Facebook (2004), YouTube (2005) y Twitter (2006). En ese transcurso de tiempo, al usuario solo le basta tener un teléfono inteligente y acceso a datos para interactuar en estas ${ }^{4}$. Cada una de estas le ha permitido extender sus dinámicas de socialización, desde lo laboral a lo amical, desde lo audiovisual a lo informativo.

La presencia de las redes sociales en la experiencia individual y colectiva de los seres humanos no tiene una vocación hegemónica y (al igual que los medios masivos del siglo $\mathrm{XX}$ ) generan voces a favor y en contra. Al respecto, Zygmunt Bauman afirmaba que las personas emplean las redes sociales "no para unir, no para ampliar sus horizontes, sino por el contrario, para encerrarse en lo que llamo 'zonas de confort', donde el único sonido que oyen es el eco de su voz" (De Querol, 2016). El problema surge cuando las personas entienden o usan las redes sociales como la realidad misma, sin comprender que son solo un ámbito más de ella. La socialización se aprende y se desarrolla también con el contacto entre los seres humanos y es un proceso que debe partir desde el ámbito físico y presencial para extenderse al virtual.

4 Según Ipsos Perú (2018), el adulto joven peruano comprende una población de 6.3 millones de habitantes, los cuales son digitales (85\%), es decir, que se conecta a Internet por lo menos una vez por semana; el $61 \%$ tiene smartphone, el $24 \%$ usa Netflix y el $15 \%$ realiza compras por Internet. 
La virtualización de la existencia supone una falta de relación interpersonal, donde las redes sociales asumen la función de "contenedor" de las experiencias sociales. En la actualidad, no se puede dejar de reconocer a las redes sociales como espacios donde el hombre desarrolla su experiencia vital. Al respecto, Sarah Pink, citada por Aragón (2016), sostiene que el hombre actual se desenvuelve en dos planos de existencia convergentes, la vida online y la offline: ambos son parte de su vida porque "nos movemos en un mundo que es las dos cosas a la vez. A pesar de que pueda pasar que estés físicamente lejos de una persona, puedes 'estar' con ella porque están juntos online” (Aragón, 2016). En suma, el hombre es relato y por esa misma razón las redes sociales se han convertido en espacios para el desarrollo discursivo. En ese sentido, Sanjurjo (2015) sostiene que

todos los que vivimos en redes sociales sabemos que nuestros corazones laten en ellas pegados a la inmediatez, y que por ello, gracias a los dispositivos móviles que llevamos con nosotros a todos lados, las noticias se comunican casi en el mismo minuto en que ocurren, no solo por la labor de los medios, sino porque los propios ciudadanos de a pie nos hemos convertido en narradores de todo lo que nos rodea, y cualquier suceso, por trivial que nos parezca, nos gusta publicarlos en nuestras redes sociales (p. 52).

En esta nueva dinámica comunicacional, los medios tradicionales han cedido su hegemonía. La televisión ya no es el medio predominante. También se suman las redes sociales como espacios donde los ciudadanos se informan de la realidad y producen contenidos acerca de esta, ya que no necesitan de los mass media para ser creados y difundidos. La presencia de estos medios sociales en la vida de los usuarios es cada vez mayor porque están disponibles en los teléfonos celulares. Así, la información se ha vuelvo móvil y su consumo ya no se ciñe necesariamente a la programación televisiva, la emisión radial o la versión impresa de los diarios. Qualman (2015) asegura que

ya no existe la necesidad de esperar hasta el lunes por la mañana para ponerse al tanto de los acontecimientos, porque la velocidad de los medios sociales ya nos mantiene bien informados [...] hemos cambiado de un mundo donde la información y las noticias eran propiedad de unos cuantos y se distribuían a millones, a un mundo donde la información está en manos de millones y se distribuye a unos cuantos (pp. 13-14).

En toda etapa de cambios de paradigma comunicacional, los creadores que innovan en el nuevo ámbito discursivo adoptan formulas narrativas aplicadas en medios precedentes. En las redes sociales se divulgan contenidos que tienen referencialidad narrativa propia de los mass media, pero también se están creando formatos propios de acuerdo con las posibilidades técnico-narrativas que cada red ofrece (figura 3). 
Figura 3: Modelo de traslación discursiva de los relatos en los medios.

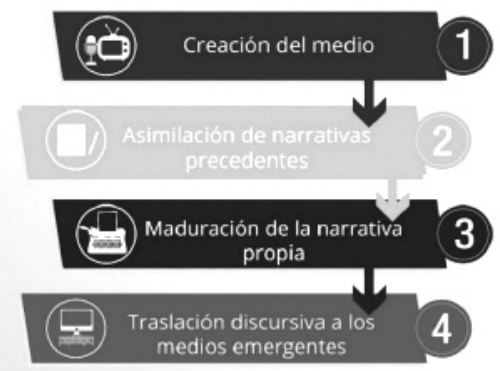

Fuente: Elaboración propia.

En este escenario narrativo, el prosumidor se convierte en un protagonista más de la mecánica discursiva contemporánea. Las redes sociales están creando contenido propio, a través de las plataformas de servicio Over The Top (OTT), que permiten la transmisión de producciones audiovisuales y otros contenidos a través de la Internet, normalmente bajo el sistema de suscripción, dejando de lado a los sistemas tradicionales de radiodifusión por señal abierta o cable. Así, el prosumidor irrumpe como nunca antes en la creación de historias a través de distintos formatos, soportes y redes (tabla 2).

Tabla 2: Tipos de contenido y su origen mediático.

\begin{tabular}{|c|c|}
\hline $\begin{array}{l}\text { CONTENIDO } \\
\text { REALIZADO POR }\end{array}$ & ESPECIFICACIÓN \\
\hline $\begin{array}{l}\text { Medios tradicionales, } \\
\text { luego volcado a redes }\end{array}$ & $\begin{array}{l}\text { Como los que producen los canales de televisión para la señal abierta y que luego } \\
\text { vuelcan en la web y en sus redes sociales. }\end{array}$ \\
\hline $\begin{array}{l}\text { Medios tradicionales } \\
\text { para redes }\end{array}$ & $\begin{array}{l}\text { Cuando los medios tradicionales producen contenidos, programas o formatos } \\
\text { para la web o redes sociales y no necesariamente para su ámbito discursivo } \\
\text { original. }\end{array}$ \\
\hline $\begin{array}{l}\text { Medios digitales } \\
\text { nativos de la web }\end{array}$ & Son organizaciones mediáticas que surgen desde y para la web y redes sociales. \\
\hline Prosumidores & $\begin{array}{l}\text { Usuarios que han encontrado en las redes sociales un espacio de comunicación } \\
\text { horizontal para distribuir sus contenidos y en el celular una herramienta de } \\
\text { creación multidiscursiva. }\end{array}$ \\
\hline
\end{tabular}

Fuente: Elaboración propia.

\subsection{El prosumidor mediático y las narrativas social media}

La denominada "tercera ola" está signada por la evolución tecnológica, en especial por la digital, que cambia los procesos de socialización, comunicación y de producción. Dentro de esta dinámica, Toffler (1981) plantea la aparición de un nuevo protagonista, el prosumidor. 
Si examinamos atentamente la cuestión, descubrimos los comienzos de un cambio fundamental en la relación mutua existente entre estos dos sectores o formas de producción. Vemos un progresivo difuminarse de la línea que separa al productor del consumidor. Vemos la creciente importancia del prosumidor. Y, más allá de eso, vemos aproximarse un impresionante cambio que transformará incluso la función del mercado mismo en nuestras vidas y en el sistema mundial (pp. 262-263).

Si bien Toffler planteó el término, McLuhan y Barrington, citados por Islas (2018), sugirieron antes que con el desarrollo de la tecnología electrónica, el consumidor también sería productor al mismo tiempo. En esa línea, McLuhan sostiene que "en la edad posteléctrica los actores comunicativos resentirían profundas transformaciones resultantes de la complejidad inherente a los nuevos ambientes comunicativos" (Islas, 2018).

Figura 4: Características del prosumidor.

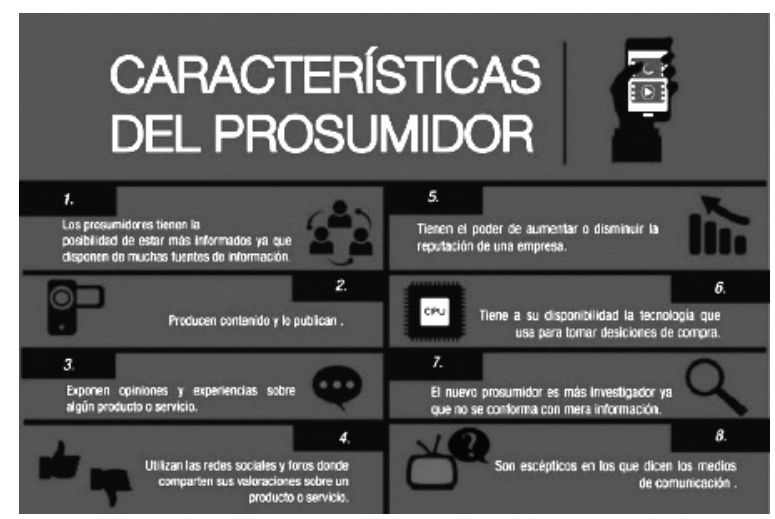

Fuente: Marketing Mobile (2018).

Con respecto a las conductas colaborativas que han desarrollado los prosumidores a partir de la web 2.0, Friedman, reseñado por Islas (2018), afirma que nunca en la historia de la humanidad los ciudadanos han compartido tanta información y la vez tener la posibilidad de buscar por sí mismos todo aquello que les interesase conocer acerca de diversos temas u otras personas. A esto denomina "in-forming":

Es la capacidad de crear y desplegar tu propia cadena de suministro, una cadena de suministro de información, de conocimientos y de entretenimiento. El in-forming tendría que ver con una colaboración individual: tú mismo eres el que investiga, edita o elige el entretenimiento, siguiendo tus propias pautas y valiéndote de tu propia capacidad y medios, sin necesidad de acudir a la biblioteca o al cine o a una cadena de televisión. El in-forming es búsqueda de conocimiento (Islas, 2018).

Como práctica de investigación y diseño de acciones (que permiten la creación de contenidos) el in-forming es aplicado por los prosumidores mediáticos, indistintamente 
del espacio narrativo que ocupen. Es así que un youtuber realizará la recopilación de la información que necesita para realizar su performance audiovisual; el creador de un meme coyuntural toma hechos de la realidad y los condensa a través de su producto gráfico textual. La diferencia con los tiempos analógicos es que ahora los prosumidores tienen a su alcance de su mano la tecnología para crear y difundir.

Vista desde una concepción genérica, la palabra "prosumidor" queda rebasada por la realidad. Su construcción semántica (productor + consumidor) sirve para denominar cualquier tipo de acción que realiza el usuario para elaborar un producto y consumirlo, pero las prácticas de la realidad obligan delinear una denominación más específica ("prosumidor mediático"), desde el punto de vista de participación en la creación informativa.

La figura del prosumidor mediático está en la base de nuevas plataformas sociales de contenido informativo. Su actividad como consumidores y productores se desarrolla plenamente a través de los gestores sociales de noticias, donde pueden subir informaciones propias, enlaces de medios, debatir, comentar, ampliar y consumir el producto informativo. Estos gestores se convierten en alternativas a la búsqueda de información, puesto que ofrecen un sistema de jerarquización social de contenidos y es en ellos en donde participa más activamente estas nuevas tipologías de audiencias prosumidoras (Marín, 2015).

Se plantea una breve clasificación de los prosumidores mediáticos: a) analógicos, b) digitales y c) móviles (figura 5). Los primeros están familiarizados con las cámaras de video en cintas magnetoscopicas (mayoritariamente VHS), grabaciones de audio en casetes o fotografías en rollos de películas y reveladas luego en papel.

Figura 5: Evolución del prosumidor mediático, según su relación con la tecnología.

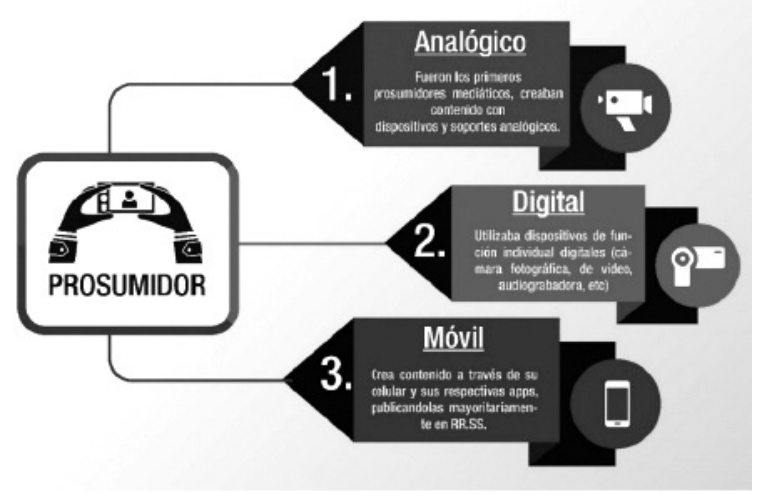

Fuente: Elaboración propia.

El segundo tipo de prosumidor mediático crea contenidos utilizando dispositivos específicos para una sola función, ya sea videograbadoras, grabadoras de sonido, cámaras fotográficas, entre otros, pero que se soportan bajo la tecnología digital: procesan la 
información en código binario y esa data puede ser trasladada luego a una computadora para ser posproducida.

En la actualidad, las funciones de producción de contenidos pueden ser hallados en un solo dispositivo: el teléfono celular. Con estos artefactos, los prosumidores móviles son capaces de crear diferentes tipos de productos a través de un solo aparato, permitiéndoles tomar fotos, crear gráficos, grabar audios y videos, ver contenidos OTT o publicar e interactuar en las redes sociales.

\section{Análisis de contenido}

Se han tomado en consideración cuatro publicaciones realizadas en la red social Facebook aparecidas en la tercera semana de julio de 2018. El criterio de selección fue aleatorio, tratando de tener la mayor variedad de unidades en cuanto a expresiones narrativas. Este es un análisis a escala reducida de lo que se pretende realizar más adelante para ir construyendo el cuerpo argumental del concepto de "narrativas social media".

La primera publicación (figura 6) fue realizada por André Machuca Chávez. El video posee una narrativa propia de los youtubers, quienes aplican la ruptura de la cuarta pared, el corte sobre el plano y el montaje yuxtapuesto con tomas de apoyo, narración verbal in situ y musicalización extradiegética. El post de Facebook está estructurado a partir del hipervínculo del video de YouTube, pero se le añade una descripción del lugar visitado por el youtuber, lo que expande la narrativa del relato.

Figuras 6 y 7: Publicaciones de Facebook.
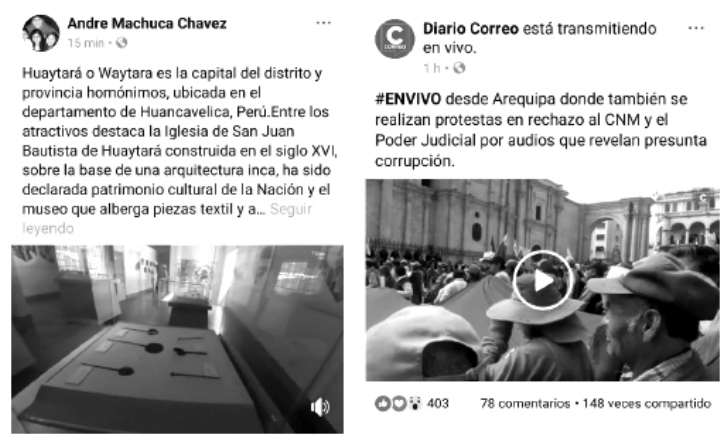

Fuentes: Machuca (2018) y Correo (2018).

La segunda publicación (figura 7) es un producto informativo que da cuenta de las protestas en la región de Arequipa. Esta publicación proviene de la cuenta oficial del diario Correo, perteneciente al grupo mediático EPENSA. Este conglomerado es uno de los que más está incursionando en diversificar contenidos para diferentes marcas (online y offline) a 
través del trabajo que realiza una sola sala de redacción, elaborando productos para las distintas plataformas que maneja (web, medios impresos, televisión, redes sociales). Este caso refleja cómo un medio, originalmente analógico y monomediático, se adapta a una estructura digital y convergente.

Figuras 8 y 9: Publicaciones de Facebook.

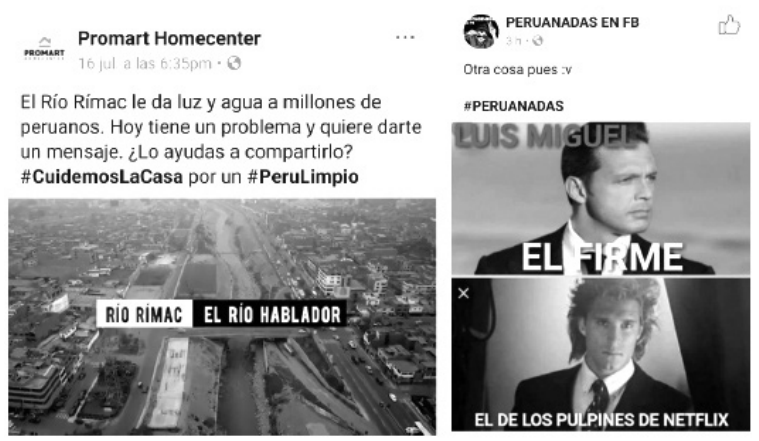

Fuentes: Promart Homecenter (2018) y Trigoso (2018).

La tercera publicación (figura 8) forma parte de una campaña de publicidad social de la empresa Promart Homecenter. Su propósito era concienciar a la población para que dejase de arrojar basura en el río Rímac, colocándose sensores de sonido que se activaban cada vez que las personas se acercaban a las orillas. Los videos de la campaña captaban las reacciones de sorpresa de los sujetos. Cabe destacar la personificación del río Rímac a través de una voz en off, lo cual reforzó el storytelling y la activación, técnicas muy utilizadas en la publicidad y que funcionan en las redes sociales. El post obtuvo más de siete mil reacciones y más de 39 mil usuarios de Facebook lo compartieron (Código, 2018).

Tabla 3: Descripción de las publicaciones de Facebook.

\begin{tabular}{|l|c|c|c|c|}
\hline & PUBLICACIÓN 1 & PUBLICACIÓN 2 & PUBLICACIÓN 3 & PUBLICACIÓN 4 \\
\hline Tipo de narrador & Prosumidor & Mass media & $\begin{array}{c}\text { Anunciante } \\
\text { publicitario }\end{array}$ & Prosumidor \\
\hline Propósito comunicacional & Información & Información & Publicidad social & Entretener \\
\hline Configuración narrativa & $\begin{array}{c}\text { Textual - } \\
\text { audiovisual }\end{array}$ & $\begin{array}{c}\text { Textual - } \\
\text { audiovisual }\end{array}$ & $\begin{array}{c}\text { Textual - } \\
\text { audiovisual }\end{array}$ & Textual - gráfica \\
\hline Narrativa para social media & Sí & Sí & Sí & No \\
\hline Vinculación a otras redes & Sí & Sí & Sí \\
\hline
\end{tabular}

Fuente: Elaboración propia. 
La cuarta publicación (figura 9) es de origen prosumer y es un formato muy usado en redes sociales: el meme. En este caso, se aprecian una secuencialidad temporal marcada por dos imágenes conectadas mediante títulos. En una aparece el cantante Luis Miguel, mientras que en la otra el actor Diego Boneta, protagonista principal de la serie biográfica del mencionado cantante, emitida por Netflix, una popular plataforma online que permite disfrutar de una considerable cantidad de series y películas, muchas de estas producciones originales de la misma Netflix. A través de este tipo de posts, la viralización y el efecto hype trascienden las redes sociales, produciéndose así una retroalimentación entre diferentes formatos y medios.

\section{Conclusiones}

Esta es una etapa de cambio de paradigma comunicacional. Así como la transición de lo analógico a lo digital modificó las formas de producción y consumo de relatos, ahora los procesos discursivos se orientan hacia las redes sociales como plataformas de distribución y consumo.

Cada red social se convierte en ámbito discursivo propio, brindado a los creadores la posibilidad de estructurar relatos multitextuales, hipervinculados y multidistribuibles. Estas condiciones están sujetas a las cualidades que son intrínsecas a la red social que se utilice para comunicar el contenido.

Los prosumidores y medios tradicionales (televisoras, radioemisoras, periódicos) tienen la posibilidad de compartir roles comunicacionales en las redes, situación antes impensable décadas atrás, cuando los mass media poseían el protagonismo y la hegemonía discursiva.

Los modos discursivos tienden a adaptarse de un medio a otro, como se aprecia en la muestra tomada de Facebook. Esto sucede cada vez que un nuevo medio irrumpe en el ecosistema comunicacional. Una vez adaptadas las formas narrativas precedentes, comienzan a madurar los modos narrativas propios del nuevo entorno comunicacional, lideradas por las redes sociales.

La predominancia narrativa que tuvieron los medios analógicos masivos durante el siglo $\mathrm{XX}$ ha cedido terreno. Las narrativas social media comparte roles discursivos con los prosumidores mediáticos, los medios tradicionales, las propias redes sociales y los medios web, todos estos creadores de contenido.

\section{Referencias}

Aragón, N. (19 de junio de 2016). La antropología y la inevitabilidad de lo digital en el mundo. Recuperado de https://redaccion.lamula.pe/2016/06/19/sarah-pink laantropologia-y-la-inevitabilidad-de-lo-digital-en-el-mundo/nayoaragon/

Código (18 de julio 2018). El río Rímac se hizo escuchar en la última campaña de Promart Homecenter. Recuperado de https://codigo.pe/creatividad/campanas/rio-rimacpromart-homecenter/ 
Correo (19 de julio de 2018). Post de cuenta institucional del diario Correo en Facebook. Recuperado de https://www.facebook.com/CorreoPeru/videos/10156890078864925/

De Querol, R. (9 de enero de 2016). Zygmunt Bauman: "Las redes sociales son una trampa". El País. Recuperado de https://elpais.com/cultura/2015/12/30/ babelia/1451504427_675885.html

Fernández, C. y Galguera, L. (2009). Teorías de la comunicación. México, DF: McGraw-Hill.

Fisher, W. (1987). Human Communications as Narrations: Toward a Philosophy of Reason, Value and Action. Columbia: University of South Carolina Press

Gutiérrez, B. (2006). Teoría de la narración audiovisual. Madrid: Ediciones Cátedra.

Gutiérrez, M. (2003). Géneros informativos en televisión. Lima: Universidad de Lima.

Ipsos Perú (2018). Perfil del adulto joven 2018. Recuperada de https://www.ipsos.com/sites/ default/files/ct/publication/documents/2018-07/adulto-joven-peruano-v4.pdf

Islas, O. (2018). La sociedad de la ubicuidad, los prosumidores y un modelo de comunicación para comprender la complejidad de las comunicaciones digitales. Razón y Palabra. Primera revista electrónica en Latinoamérica especializada en comunicación, 65. Recuperado de http://www.razonypalabra.org.mx/N/n65/varia/oislas.html

Karbaum, G. (2016). Campaña "Atletas Olímpicos del Perú". Narrativa audiovisual en la publicidad social. Correspondencias \& Análisis, 6, 101-120. Recuperado de http://www. correspondenciasyanalisis.com/es/pdf/v6/pub/campana-atletas-olimpicos-del-peru.pdf

Karbaum, G. (2017). La narración y los relatos, las historias como partes constitutivas de la humanidad. Recuperado de http://repositorio.ucal.edu.pe/bitstream/handle/ ucal $/ 205 /$ Arti $\%$ CC $\% 81$ culo $\% 20$ Karbaum.pdf?sequence=4\&isAllowed $=y$

Karbaum, G. (2018). Periodismo y transmedia: narrativa, redes y contenido. Lima: UCAL.

Lechuga, K. (2015). El documental sonoro. Buenos Aires: Ediciones del Jinete Insomne.

López Suárez, M. (2012). Literatura: relatos y tecnología. Presentación. ICONO14, 10(2), 1-5. doi: 10.7195/ri14.v10i2.504

Machuca, A. (19 de julio de 2018). Post de cuenta personal en Facebook. Recuperado de https://www.facebook.com/100002996079628/posts/1579352315507956/

Marín, A. (2015). La audiencia en los nuevos escenarios comunicativos: el prosumidor mediático en el centro. Recuperado de https://idus.us.es/xmlui/bitstream/ 
handle/11441/61401/Pages\%20from \%20Actas\%20XXI\%20Congreso $\% 20$ $\mathrm{SEP} \% 202015$.pdf? sequence $=1 \&$ is Allowed $=\mathrm{y}$

Marketing Mobile (2018). Características del prosumidor en la era de la publicidad digital. Recuperado de http://marketingmobileperu.com/preguntas-frecuentes/ caracteristicas-del-prosumidor-en-la-era-publicidad-digital/

McLuhan, M. (2009). Comprender los medios de comunicación, las extensiones del ser humano. Barcelona: Paidós.

Promart Homecenter (16 de julio de 2018). Post de cuenta institucional Promart Homecenter en Facebook. Recuperado de https:/www.facebook.com/ PROMARTHomecenter/videos/1786919671395512/

Qualman, E. (2015). Socialnomics. México, DF: Grupo editorial Patria.

Radio Programas del Perú, RPP (18 de diciembre de 2014). Conoce de dónde proviene el término "chibolo pulpín”. Recuperado de http://rpp.pe/tecnologia/mastecnologia/conoce-de-donde-proviene-el-termino-chibolo-pulpin-noticia-752140

Real Academia Española, RAE (2018). “Lenguaje”. Recuperado de http://dle.rae.es/srv/ fetch?id=N7BnIFO

Rincón, O. (2006). Narrativas mediáticas, o cómo se cuenta la sociedad del entretenimiento. Barcelona: Gedisa.

Rodríguez, M. (1989). Manual de creatividad: los procesos psíquicos y el desarrollo. México, DF: Trillas.

Sanjurjo, B. (2015). Periodismo y redes sociales. En B. Andueza (Ed.), Periodismo digital y televisivo (pp. 47-64). Madrid: Dykinson.

Statista (2018). Penetración de Internet en Latinoamérica. Recuperado de https://es.statista. com/grafico/13903/cuantos-usuarios-de-internet-hay-en-america-latina/

TEDx Talks (22 de diciembre de 2014). ¿Para qué sirve la historia? Felipe Pigna. TEDx Tandil [video de YouTube]. Recuperado de https://www.youtube.com/watch?v= zPUgdqCkiQ

Toffler, A. (1981). La tercera ola. México, DF: Edivisión.

Trigoso, E. (19 de julio de 2018). Post de cuenta personal en Facebook. Recuperado de https://www.facebook.com/675798430/posts/10156485107543431/ 